\title{
NHS Commissioning 'very concerning'
}

$\mathrm{T}$ he BDA has called for the next government to end competitive tendering across the NHS, after the latest fiasco saw a process for commissioning orthodontic services across parts of the West Midlands abandoned yesterday after over 6 months. The decadelong contracts are estimated to be worth over $£ 65$ million.

The process has seen major delays as administrative failings by NHS England have potentially forced the reopening of tenders, while similar moves across other English regions have been facing legal challenges. Practices across the West Midlands have been left uncertain about the future of the process.

In some circumstances children who have been waiting for years to start orthodontic treatment on the NHS may face going to the back of the queue when current providers lost their contracts, with existing patients potentially running the risk of long journeys if they did not live near one the new providers.

Dentist leaders say tendering processes place huge stress on dedicated practices and encourage a race to the bottom in a bidding war to deliver NHS services at the cheapest price. The BDA is aware of contracts in NHS Southern region, that have already been handed back by successful bidders owing to lack of staff.

Providers have already spent considerable time, energy and money putting together bids - with companies providing support on writing bids at costs of up to $£ 30,000$. Emails were sent to all current bidders in the West Midlands region by NHS England.

The BDA is calling on all parties to scrap tendering, and for special consideration for the many high performing practices that have lost their contracts during this process.

BDA Chair Mick Armstrong said: 'This fiasco shows why it's time to end this race to the bottom in our NHS.

'Children could face going to the back of the queue for braces, or switching provider months or years into a course of treatment. Meanwhile practitioners are already facing huge costs and stress in a bidding war to deliver NHS services at the cheapest price.

'Across England contracts have been taken from committed practitioners and handed to providers without the staff to deliver on them. All on the basis of a paper exercise rather than a serious examination of their capability.

'The next government should not be applying a 'Seaborne Freight' model to NHS services. This sort of 'competitive' tendering does nothing to improve quality and only jeopardises continuity of care.

'NHS orthodontists should not have to squander precious clinical time on a failed process that has a material impact on patients.'

The British Orthodontic Society (BOS) has also voiced their concerns about the recent abandonment by the Midlands and East Commissioning team of some lots in Batch 2 of its procurement process.

The BOS is monitoring the situation closely and seeking further information

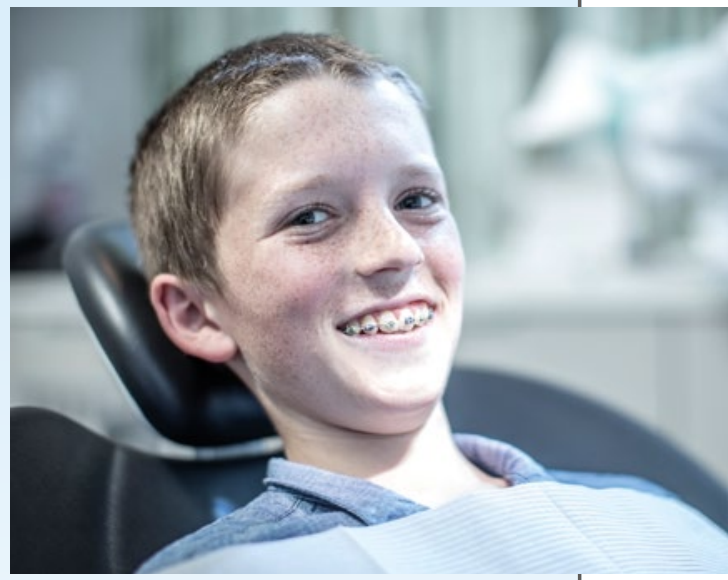

from NHSE but, at the current time, there is no clarity over the reasons for this decision and announcement or the future for the affected contracts and bidders within the procurement. Equally it is not clear if there will be further announcements in a similar vein.

Jonathan Sandler, BOS Chair, commented: 'We are very concerned about the impact that this further delay could have on patients in or waiting to start treatment.

'The continued uncertainty that this means for committed orthodontists who have spent large amounts of both money and effort on the tendering process is very disappointing and unsettling, especially when this means planed investment in services is further delayed. We hope NHSE will be forthcoming with further information and a plan to move forward as soon as possible.'

\section{DDU calls for GDC to be given powers to reform fitness to practise process}

The GDC has made some positive improvements in the way it regulates the profession but it must be given the powers needed to make further reforms, the Dental Defence Union (DDU) has said.

Responding to the GDC's publication of its strategy for the next three years 2020-2022 strategy, Right time. Right place. Right-touch, head of the DDU, John Makin said: 'Regulators' investigations carry a stigma and generally those being investigated perceived them as punitive, even if that is not the purpose. The
GDC's welcome emphasis on learning from what goes wrong and sharing that learning in order to assist dental professionals to continue to practise safely is an approach that I'm sure will be widely appreciated.

'It's reassuring that the GDC has been in discussions with the Department of Health and Social Care (DHSC), the PSA and other regulators about the need to reform its powers to amend its procedures.

'The GDC has already made positive changes, such as amends to its website which have contributed to a reduction in the number of fitness to practise concerns overall and the introduction of triage and Case Examiners in fitness to practise (FTP) procedures.

'Being investigated is stressful for most dental professionals and it has been clear for a long time the GDC should be given the powers it needs to amend the FTP procedures in a more efficient way. With the right safeguards in place, this could make a real difference.' 